\title{
Os processos comunicacionais na política de formação de professores a distância
}

\section{The communicational processes in policies of distance teacher training}

\author{
Magalis Bésser Dorneles Schneider ${ }^{1}$ \\ Raquel de Almeida Moraes ${ }^{2}$
}

\begin{abstract}
RESUMO
$\mathrm{O}$ artigo apresenta o resultado da pesquisa sobre os processos comunicacionais na Política de Formação de Professores a distância na perspectiva dialógica, tomando como base empírica o curso de Pedagogia de um polo da Universidade Aberta do Brasil. O objetivo que norteou a pesquisa foi analisar o tipo de comunicação entre tutor e alunos. A metodologia utilizada foi o estudo de caso com abordagem dialética. Os resultados apontaram para a negação da comunicação como diálogo construtivo, crítico e emancipador. O discurso explícito foi o da contra-hegemonia capitalista, porém as práticas analisadas foram ideológicas, de falsa consciência, não expressando a superação da alienação. Como conclusão, pontua-se que a possibilidade de ocorrer uma comunicação emancipadora nos cursos de formação de professores somente será possível a partir de uma política de formação que articule teoria e prática, discurso e realidade numa construção coletiva do sentido da práxis que transforme e supere a hegemonia tecnicista, de gerenciamento e da massificação.
\end{abstract}

Palavras-chave: formação de professores; comunicação emancipadora; educação a distância.

\footnotetext{
ABSTRACT

The article presents the results of a research on communication processes in the Teacher Education Policy in the distance dialogical perspective, taking

DOI: $10.1590 / 0104-4060.39421$

1 Universidade Federal de Goiás. Campus Jataí. Jataí, Goiás, Brasil. Rua Riachuelo. CP

2 Universidade de Brasília. Campus Universitário Darcy Ribeiro, Faculdade de Educação. Brasília, Distrito Federal, Brasil. CEP: 70.910-900.
} 03. CEP: 75804-020. 
as an empirical basis the pedagogy course from a pole of the Open University of Brazil. The goal that guided the research was to analyze the type of communication between teacher/tutor and students. The methodology was based on the materialist dialectics and the delineation adopted was a case study. The results pointed to the denial of communication as constructive, critical and emancipatory dialogue. This open speech was against the capitalist counter-hegemony, but the analysed practices were ideological, of false consciousness, not expressing the overcoming of alienation. As a conclusion, we point out that the occurrence possibility of an emancipatory communication in teacher training courses will only be viable through a formation policy that articulates theory and practice, discourse and reality in a collective construction of praxis meaning which transforms and overcomes the technicist hegemony, management and massification.

Keywords: teacher training; emancipatory communication; distance education.

\section{Introdução}

A comunicação na educação a distância é uma das molas propulsoras das mudanças que ocorrem a partir das novas Tecnologias da Informação e Comunicação (TIC), exercendo um fascínio sobre as pessoas, suscitando outros conceitos, valores, relações sociais e de poder. Para Lima (2011, p. 22), o próprio significado original da palavra "Comunicação" já causa um problema de ambiguidade. Etimologicamente, a palavra "Comunicação" tem sua origem no latim "communis" que significa comum, "a ação de tornar comum", um substantivo de ação, fazer conhecido, "tornar comum, fazer saber". (LIMA, 2011, p. 22, grifo do autor). Contudo, a palavra comunicação carrega uma ambiguidade, que está representada por dois extremos; primeiro, transmitir algo que foi apropriado e depois é passado para outro. Nesta perspectiva a comunicação é um processo unidirecional, pois a ação de comunicar se dá em um só sentido, não havendo uma coparticipação, uma comunhão, um encontro de saberes. Já no segundo, tem-se o sentido de compartilhar, usar ou possuir algo em comum com alguém, tornar conhecido o que foi produzido. Nesta perspectiva se compartilha algo numa coparticipação, uma comunhão, um encontro de diálogos que se desenvolve numa interação comunicativa.

Este artigo é o resultado de uma pesquisa sobre os processos comunicacionais no curso de Pedagogia a distância de um polo da Universidade Aberta do Brasil no Estado da Bahia. O objetivo foi pesquisar o tipo de comunicação presente entre professor/tutor e aluno, a partir da classificação de Lima (2011). 
Partiu-se do pressuposto de que a comunicação como educação, numa perspectiva de emancipação, poderá romper com a lógica imediatista da formação de trabalhadores em educação para o mercado de trabalho. E a partir de uma comunicação dialógica possibilitará uma educação com uma consciência crítica, participante e com intuito de intervir e contribuir com a realidade onde se vive. A hipótese diretriz foi que a comunicação entre professor e aluno terá uma perspectiva emancipadora se existir um diálogo crítico, contextualizado com a realidade, superando, dessa maneira, uma lógica dominante e excludente.

As inquietações foram: É possível uma educação a distância problematizadora nos cursos de formação de professores? Quais os limites e as possibilidades de uma comunicação como diálogo emancipador nos cursos de formação de professores a distância? A formação de professores a distância enseja uma transmissão de conteúdos? A comunicação presente nos cursos de formação de professores a distância contribui para uma formação crítica ou apenas reprodutiva, manipuladora de trabalhadores para o mercado de trabalho?

\section{Aspectos metodológicos}

A orientação metodológica esteve pautada na dialética materialista entendida enquanto ciência das leis gerais do movimento, que busca compreender a totalidade nas suas relações, interações, interconexões, num movimento constante em que as contradições vão sendo transformadas em unidades de conhecimento, para logo depois se tornarem contraditórias. (GADOTTI, 2000). A dialética possibilitou estudar as contradições, interpretar a realidade, o fenômeno do movimento e a totalidade para compreender como se movimentam e se interpretam. (KOSIK, 2002).

Este estudo também implicou o procedimento do estudo de caso, que representa uma modalidade de pesquisa científica. Os estudos descritivos ou de caso têm o intuito de conhecer a comunidade, seus traços característicos, suas gentes, seus problemas, suas escolas, seus professores, sua educação. O estudo descritivo, assim, tem o intuito de descrever com exatidão os fatos e fenômenos de determinada realidade. (TRIVIÑOS, 1987).

O curso selecionado para a pesquisa empírica é integrante do sistema Universidade Aberta do Brasil - UAB, que oferece cursos a distância de graduação para todo o Brasil. No curso estudado, os atores são classificados em: professores (autores, revisores, supervisores), tutores (a distância e presencial), discentes, coordenadores de tutoria, coordenador pedagógico e coordenador de polo. (BRASÍLIA, 2011, p. 31). 
O curso escolhido foi o de Pedagogia por haver uma grande procura dos cursos de licenciaturas a distância, especificamente o curso de Pedagogia, conforme o Censo da Educação Superior de 2010 e 2011. (BRASIL, 2012). A pesquisa voltou-se para a ação do tutor a distância, elo entre o professor (autor, revisor e supervisor), o conteúdo e o discente na plataforma. Sua principal tarefa "é facilitar o processo de ensino aprendizagem, orientar, motivar e aconselhar os alunos, mediar os fóruns e as tarefas programadas e avaliar as atividades produzidas, sempre em parceria com o professor supervisor e o tutor presenciais". (BRASÍLIA, 2011, p. 34).

A pesquisa empírica concentrou-se no ambiente virtual do polo e, além das entrevistas com os tutores a distância (três), houve também a observação participante, análise documental e acompanhamento de dois encontros presenciais no polo de Carinhanha, BA. As entrevistas foram realizadas de modo individual e algumas em grupo nos encontros presenciais do polo. Os critérios de escolha dos entrevistados foram a facilidade de acesso e a aceitabilidade daqueles que se dispuseram a responder o questionário.

Os resultados foram interpretados por meio da análise de conteúdo tal como proposta por Franco (2005), tendo como ponto de partida a mensagem, seja ela verbal (oral ou escrita), gestual, silenciosa, figurativa, documental ou diretamente provocada. Desse modo torna-se indispensável considerar a relação que vincula a emissão das mensagens, que pode ser uma palavra, um texto, um enunciado ou até mesmo um discurso, às condições contextuais de seus produtores.

Após extrair os sentidos das mensagens, estes foram separados segundo a classificação: diálogo ou transmissão. Estes termos são entendidos, conforme Lima (2011): Diálogo: participação, comunhão, um encontro compartilhado de significados.

Transmissão: um processo unidirecional de repasse de significados.

\section{Resultados e discussões}

$\mathrm{Na}$ análise das respostas do polo selecionado, o tipo de comunicação verificada nos fóruns, nos documentos e nas entrevistas indicou características de transmissão, com o agravante de se passar por interação, diálogo, criticidade, expressando uma realidade que democratiza e emancipa o educando. A falsa ideia da existência de comunicação como interação aparece, por exemplo, no fórum de notícias. No entanto, este não apresenta notícias, nem há interação, reflexão, limita-se às orientações e informações das atividades da disciplina. 
Verificaram-se, ademais, tanto nos fóruns, nos documentos como nas entrevistas contradições nas ações, declarações de uma comunicação que não supera uma perspectiva da transmissão de informações e de controle político e econômico.

Mesmo quando se referiam às dúvidas pertinentes ao material didático os tutores eram objetivos e orientavam os alunos a consultarem os conteúdos disponibilizados na plataforma virtual. Percebe-se, assim, que a comunicação não teve o objetivo de dialogar, refletir, mas apenas de direcionar e orientar estudos e sanar dúvidas, considerando que os fóruns pesquisados e analisados foram os que se declaravam destinados ao debate, à discussão e à reflexão.

Constatou-se a falta de comunicação como diálogo nas próprias reuniões, tendo mais comunicados, planejamentos, orientações e direcionamentos. Entende-se que a comunicação como diálogo constrói a pessoa, por isso aqueles que reprimem o falar e o refletir estão conspirando contra a formação das personalidades, formação de uma sociedade melhor. (DIAZ BORDENAVE, 1983).

De acordo com os entrevistados percebeu-se que as atribuições de tutor são entendidas como acompanhar, orientar, gerenciar e avaliar as atividades dos alunos, inclusive como suporte técnico e social. Desta forma, nenhum dos tutores compreende que o seu papel é de interagir, dialogar, contextualizar a realidade dos alunos ou suscitar o pensar, mas de transmitir conteúdos, regras e ajustamentos. A falta de liberdade que os professores tutores têm para dialogar nas reuniões e encontros torna-se também um agravante para a compreensão do seu papel, haja vista que apenas seguem o que foi comunicado pelos professores e gestores.

O processo de comunicação nos ambientes colaborativos como sala de bate-papos, fóruns, memorial, web conferência foram avaliados como sendo essenciais para a aproximação de professores tutores, alunos e coordenação. Todavia, nas mensagens analisadas dos fóruns e nas entrevistas verificou-se a ausência da comunicação como diálogo que contribuísse reflexiva e criticamente para o processo de formação e emancipação. Percebe-se que a práxis educativa, a unidade teoria-prática, não condiz com a realidade desses educadores, pois no verbalismo confirmam um discurso de teoria sem prática. (SAVIANI, 2008).

Concernente aos processos de comunicação (se dialógicos, horizontais ou verticais, unidirecionais), presentes no curso, não houve um consenso nas respostas dos tutores. Teve uma tutora que afirmou que o processo predominante era o vertical entre professor, conteúdo e estudante, acrescentando que na maioria das vezes o tutor não teve autonomia para dar opiniões, eximindo assim a possibilidade de qualquer tipo de comunicação como diálogo.

Nos fóruns analisados no ambiente virtual de aprendizagem o processo de comunicação que mais se apresentou foi o vertical. Dessa forma, demonstrou-se que há transmissão de informação, mas não ocorreu o diálogo numa dimensão 
política da comunicação e do direito à voz. Nesta perspectiva, os educandos são tratados como sujeitos passivos, cabendo à educação apassivá-los ainda mais para adaptá-los ao mundo.

No entanto, os tutores afirmaram ser um diferencial o processo de comunicação como diálogo crítico, articulado com a realidade "[...] os processos comunicacionais devem ser críticos e flexíveis em prol do bom andamento do curso e para que os objetivos possam ser alcançados." (Tutora Jane). Todavia, incoerente com a prática observada e realizada nos fóruns pesquisados.

No que se refere ao planejamento de tutoria as respostas foram unânimes, pois os professores tutores disseram não haver planejamento de tutoria, eles apenas seguem as orientações da professora supervisora. Privilegia-se assim uma relação vertical numa visão que estimula a ingenuidade, a falta de criticidade, fortalecendo os interesses opressores.

Percebe-se que os professores tutores compreendem os processos da comunicação como uma possibilidade técnica, porém a comunicação não é vista como educação numa perspectiva emancipatória. Situações assim ilustram a racionalidade tecnológica, transformando a força crítica em força de ajuste e submissão. (KELLNER, 2006). A autonomia perde seus sentidos à proporção que os pensamentos, ações, são moldados pelas técnicas do aparato que o homem mesmo criou.

A questão da política de formação de professores a distância é compreendida pelo tutor como uma maneira de expandir a educação com baixo custo. Os tutores afirmam que é perceptível o propósito de apenas dar diplomas melhorando os dados estatísticos. Conforme expressa a tutora Michelle: "Cheguei a ouvir de gestores que as verbas são poucas, a qualidade ainda não é a melhor, mas ainda é melhor do que nada [...]".

As dificuldades percebidas na perspectiva da interação do professor tutor e aluno foram pontuadas como as de ordem técnica e de domínio das ferramentas para trabalhar na plataforma no ambiente virtual. A máquina dessa forma subordina, domina sua vida e a submete à factualidade de um mundo em que a máquina é o fator e o ser humano apenas o instrumento. (MARX; ENGELS, 2002).

No que se refere aos pontos positivos a resposta que se destacou foi a da professora tutora que mencionou o curso como uma possibilidade da democratização da educação:

Os pontos positivos são muitos. A educação a distância veio proporcionar aos alunos que não tiveram oportunidades de fazer um curso presencial, que agora façam por meio da internet, ou seja, on-line. Muitos desses sujeitos trabalham e quase não sobra tempo ou oportunidades de fazer uma faculdade presencial. (Tutora Marisa). 
Os entrevistados sugeriram cursos de capacitação em educação a distância para os tutores, que ajudem a dominar e explorar a plataforma e também a interagirem a partir de ferramentas nesse ambiente de aprendizagem on-line. Percebe-se que a concepção da comunicação como educação emancipadora é reduzida ao domínio de equipamentos e de ferramentas. A perspectiva técnica se sobressai também nas respostas quanto às mudanças sugeridas pelos tutores. É ressaltado o domínio dos equipamentos, programas e a operacionalidade técnica dos polos e a parte da comunicação dialógica e pedagógica é esquecida.

Os encontros presenciais com os alunos demonstraram que há planejamentos dos encontros, porém é destinado pouco tempo para a reflexão e articulação com a realidade, pois é proposto um prazo maior para as orientações, informações e dúvidas dos alunos. Constata-se novamente que a comunicação apresentou-se mais como uma transmissão de comandos, regras, prazos e direcionamentos. Contudo, na observação participante foi possível constatar a diminuição do orçamento pelo governo destinado ao Programa Universidade Aberta (UAB), refletindo assim na diminuição dos encontros presenciais.

As discussões resumiram-se em orientações para o estágio, relatório final e para o seminário de encerramento do semestre. Ao final do primeiro encontro os alunos manifestaram a importância e a necessidade de haver mais encontros presenciais durante o semestre.

Os alunos reforçam a relevância dos encontros quando afirmam que o acompanhamento on-line pelos professores tutores é importante, pois eles sempre respondem as dúvidas, sugerem leituras, são atenciosos, contudo, não há como obter respostas tão rápidas como no presencial. Inclusive duas alunas mencionaram: "[...] com o professor tutor nos encontros presenciais eu aprendo em uma hora coisas que levaria dias para ler e entender". Outra aluna complementa: "[...] andamos quilômetros em poucos minutos".

No entanto, alguns alunos disseram que é preciso que os cursos a distância sejam revistos, pois se apresentam muito distantes: "Eu aprendi muito com o curso, com as disciplinas, perto do que eu sabia antes, hoje sou outra pessoa, mas eu vejo a educação a distância muito distante, pois aprendi mais, mais tive que correr muito atrás". Outra aluna acrescenta que o aluno ainda sente-se muito solitário. E diz “[...] seria bom que tivéssemos pelos menos uma aula por semana, aí seria perfeito".

Outra dificuldade relatada pela aluna é o preconceito das pessoas quando sabem que o curso foi feito a distância, ela disse: "Ainda há o tabu quando ficam sabendo que o curso é a distância".

No que tange à comunicação entre tutor e aluno disseram que a maioria dos professores tutores é atenciosa e responde as mensagens, porém salientam que não são todos, pois têm alguns que demoram a responder e sempre dizem 
que as atividades estão boas, parabenizam, sem solicitar reformulações ou questionarem.

O Projeto Político-Pedagógico do curso de Licenciatura em Pedagogia, o Projeto Acadêmico do Curso de Pedagogia a Distância e os Guias de Estudo das disciplinas apresentaram como objetivo principal a necessidade da constante formação em decorrência das exigências do mundo globalizado e das constantes mudanças. No Projeto Político-Pedagógico é ressaltada a importância das tecnologias da comunicação e informação para a ampliação dos conhecimentos e informações em prol de uma formação contínua e em fluxos não lineares. Ressaltaram que para isso ocorrer será preciso uma mudança pedagógica que favoreça estilos personalizados e o aprendizado colaborativo em rede, valorizando as competências adquiridas individualmente, porém não há clareza do que seriam essas competências adquiridas individualmente (fazer, pensar, executar, dialogar...) e como essas questões seriam trabalhadas a distância.

Percebe-se, inclusive nos documentos, a comunicação como um processo linear, mecânico, numa perspectiva de administração da educação a distância, ao invés de suscitar metas e estratégias para se atingir uma educação a distância de qualidade.

No Projeto Político-Pedagógico e no Projeto Acadêmico do Curso de Pedagogia a Distância são abordados os desafios, as necessidades de articular os elementos filosóficos, teóricos e metodológicos que envolvem pessoas e grupos específicos. No entanto, percebe-se que há uma lacuna no que se refere à comunicação, pois não é mencionada e muito menos salientada a importância da comunicação entre professores tutores, alunos e gestores. Os documentos resumem-se a instruções, direcionamentos e administração da educação a distância.

A grande questão é como ter diálogo uns com os outros? Diálogo entre aqueles que desejam dar nome ao mundo e os que tudo fazem para que isso não ocorra? Assim, o humanismo tecnológico reduz a educação a um conjunto de metodologias e de instrumentos que despolitiza a grande massa da população. (FREIRE, 2011).

Os documentos também ressaltam que o Projeto tem como objetivo formar educadores capazes de intervir na realidade de maneira crítica, contextualizada, ética, buscando a plena realização individual e coletiva, comprometidos com um projeto de sociedade autônoma, solidária e democrática. No entanto, a dimensão prática, política ou social só adquire plena significação quando compartilha uma luta concreta dos homens para libertarem-se. (FREIRE, 2005, 2007).

Menciona-se nos Projetos e nos Guias de Estudos que o ensino comporá a pesquisa e a extensão por meio de projetos integrados para articular o fazer, o pensar pedagógico e a atuação em diversos contextos socioculturais e 
organizacionais. Todavia, os projetos de intervenção construídos não tiveram continuidade, muito menos suscitaram um espírito científico de repensar ou mudar uma realidade.

Os Guias de Estudos pesquisados apresentaram uma proposta de trabalho para o semestre, planejamentos, cronograma de atividades e orientações de estágios. Percebeu-se que a comunicação entre tutor e aluno não foi comentada, pensada, apenas afirma-se que as tecnologias da informação e comunicação (TIC) são um desafio para a comunicação educacional. Dessa forma, uma educação sem comunicação legitima e submete ao domínio de uma educação despolitizada, sem criticidade, marginalizada, sem a possibilidade de transformação, problematização ou de construção de uma educação como comunicação dialética. (SAVIANI, 2009).

Assim, os documentos apresentam-se como informativos e conteudistas, com o foco nas orientações técnicas, didáticas, pedagógicas de estudos e prazos da disciplina. Os Guias de Estudo e os Projetos propõem três encontros presenciais nos polos durante o semestre, porém na prática ocorreram somente dois.

Percebe-se que os objetivos declarados nos documentos são uma coisa, mas na prática a situação é outra. Havendo assim um processo de incomunicação, em que poucos mandam e muitos executam, vivendo a falta de manifestações de comunicação, intercâmbio e diálogo. (TEIXEIRA, 1983).

A ausência de comunicação como diálogo reflete a falta de Políticas Públicas eficazes, sérias e comprometidas com a educação de qualidade, o que transforma o cenário da formação de professores a distância no Brasil em lugar de treinamento de trabalhadores para o mercado de trabalho. A transmissão de conteúdos e informações torna-se oportuna diante da falta de seriedade das políticas de investimentos e manutenção para o desenvolvimento de uma educação a distância de qualidade que priorize o pensar, criticar e transformar.

A proposta inicial do programa da Universidade Aberta do Brasil de democratizar e universalizar a educação aparece mais como uma política de formação precária de trabalhadores na educação, organizada para o mercado de trabalho (pós-fordista) com características de racionalização e produção em massa.

No âmbito das reformas relativas à política de formação de professores a distância, o Estado brasileiro é subordinado às recomendações dos Organismos Internacionais (OIs) desde a década de 1990. (BARRETO, 2001).

Essa tendência à expansão do ensino superior tem as características políticas e ideológicas na própria Constituição Federal de 1988, no Art. 205, que menciona a Educação como sendo direito de todos e dever do Estado e da família, sendo promovida e incentivada com a colaboração da sociedade, visando ao pleno desenvolvimento da pessoa e seu preparo para o exercício da cidadania e qualificação para o trabalho. 
A Lei de Diretrizes e Bases da Educação Nacional - LDB nº 9.394/96 contribui com essa expansão quando suscita um caráter de democratização à Educação Superior, mencionado no Art. 80 da LDB e regulamentado a partir do Decreto $\mathrm{n}^{\circ} 5.622$, de 19 de dezembro de 2005. Dessa forma, o Poder Público incentivará o desenvolvimento e a veiculação de programas de ensino a distância, em todos os níveis e modalidades de ensino e de educação continuada.

A promulgação dessas leis suscitou ações com a ideia ilusória de democratização da educação, uma estratégia de capacitação de professores em serviço e certificação em nível superior.

A Universidade Aberta do Brasil (UAB) foi idealizada no âmbito do Fórum das Estatais pela Educação em 2005 com o principal objetivo de capacitar professores da Educação Básica e buscar interiorizar a oferta de cursos e programas de Educação Superior, prioritariamente para formação inicial e continuada de professores com a utilização de metodologias de educação a distância. A UAB, dessa forma, surge como uma estratégia exponencial de oferta de vagas no ensino superior, elevando o nível de atendimento sem aumentar recursos necessários. O uso das novas tecnologias educacionais surge como uma forma de solução para o problema de formação docente e como uma maneira de universalizar a educação no contexto do capitalismo de uma maneira mercantil e instrumental. (FREITAS, 2007).

Percebe-se que a falta de comunicação como diálogo na formação de professores a distância decorre principalmente da falta de políticas públicas sérias para a formação desses profissionais. Persiste o discurso da democratização mascarado num ajustamento político e econômico governamental, configurando uma estratégia ilusória de homogeneização da educação. O pós-fordismo surge como uma maneira mais justa e democrática do capitalismo do futuro.

A política aparece nos polos da Universidade Aberta como um jogo de interesses políticos partidários num princípio de domínio eleitoral, utilizando-se do discurso da democratização da educação. A escassez de recursos e verbas para proporcionar mais encontros presenciais ou bolsas assim como valores mais justos para professores está disfarçada numa ideologia que aparece como boa para todos, que representa interesses comuns, mas que na verdade fortalece ideias e interesses de uma pequena parcela que conserva e internaliza desigualdades.

As ações na educação a distância demonstram a escolha dessa política de formação de professores a partir do discurso do uso intenso das tecnologias educacionais e a relação custo e benefício como definidora dessas atividades formativas. A formação a distância tem como base o Art. 87, parágrafo $3^{\circ}$, inciso III da LDB, que define a realização de programas de formação para todos os professores em exercício, utilizando para isso também os recursos da educação a distância. 
A expansão da educação a distância com a criação da Universidade Aberta do Brasil (UAB) integrada às Universidades Públicas brasileiras tem como objetivo formar professores da Educação Básica, contudo, há uma contradição quando comparada ao tripé das Universidades Públicas, que é de ensino, pesquisa e extensão, pois os cursos oferecidos a distância estão mais voltados para o ensino do que para a pesquisa e a extensão.

Isso se torna um grande desafio da educação como emancipação, diálogo quando se está diante da negação do diálogo, falar quando não se tem uma escuta do que o outro tem a dizer, comunicar-se diante da incomunicação. A educação reflete a estrutura do poder, daí a dificuldade que tem um educador dialógico de atuar coerentemente numa estrutura que nega o diálogo. Algo fundamental, porém, pode ser feito: dialogar sobre a negação do próprio diálogo. (FREIRE, 2005).

Ao contrário, o que presenciamos é o domínio da ideologia (entendida enquanto visão de mundo), da qualidade total, formação flexível, polivalente e do conhecimento. (SCHNEIDER, 2013).

\section{Conclusão}

Este artigo apresentou os resultados da pesquisa referente aos processos comunicacionais na formação de professores a distância de uma instituição pública. O objetivo norteador foi analisar o tipo de comunicação entre tutor e alunos. Partiu-se do pressuposto de que a comunicação entre professor e aluno será emancipatória se existir um diálogo crítico articulado com a realidade. A análise da perspectiva dialógica entre professor e aluno no curso pesquisado indicou que prevaleceu a concepção de transmissão de conteúdos e atividades. Ademais, identificou-se a existência de conflitos e contradições nas práticas de comunicação entre tutor e aluno, nos encontros presenciais e entrevistas.

A comunicação presente no curso não contribui para uma formação crítica, emancipadora, política, já que os processos comunicacionais privilegiaram a instrução, reprodução e passividade, numa separação do trabalho intelectual e manual, em que a teoria e a prática passam a ser duas realidades independentes. Assim, o discurso do curso é contra a hegemonia da classe capitalista, porém suas práticas ainda são ideológicas, de falsa consciência, não expressando a superação da alienação.

Não há estratégias de comunicação que visem dialogar e interagir. As contradições estão presentes entre o que é declarado nas entrevistas e nos documentos. 
Confirmou-se que há interesses individuais e não coletivos, uma ideologia que serve para camuflar os interesses reais apresentando-se como uma explicação verdadeira do mundo e que corresponde aos interesses de todos.

A perspectiva política do polo analisado, envolvendo partidos políticos, faz com que a educação seja tida como um objeto de manipulação, ascensão e popularidade, um ponto favorável para o ingresso na política.

A educação a distância não poderá ser considerada como uma alternativa apenas para multiplicar alunos sem antes alterar os quadros docentes e os investimentos. Comparando-se a uma fábrica, uma empresa que objetiva apenas ter estratégias para aumentar a produção de cursos, quantidade de acessos, resultados quantitativos, planejamento de currículo, preparação de roteiros de cursos, produção audiovisual, textos de acompanhamento, atendimento ao aluno e várias formas técnicas e tecnológicas para alienar, mecanizar e adestrar as pessoas.

As políticas educacionais têm um discurso de expansão da educação que exprimem um discurso de práticas descentralizadoras, ideológicas, porém contraditórias diante da realidade dos polos da UAB e do descaso com a falta de recursos públicos para a manutenção do programa.

Ao contrário, é preciso suscitar uma consciência de ver o mundo, de refletir sobre as ações, uma consciência crítica, de vivência e de pensar a educação como um ato político. A comunicação como formação para emancipar não pode ter uma prática inconsciente na continuidade do controle e da transmissão, sendo uma ameaça ao monitoramento e fiscalização das ações.

Os limites da comunicação como diálogo estão arraigados no tecnicismo e na mecanização que se sobrepõe ao ato de pensar, discutir e criticar. Numa concepção que silencia os educandos, em que os educadores limitam-se a transmitir informações, o que precariza os trabalhadores de educação levando-os à proletarização do trabalho docente, mantendo assim a dicotomia entre o saber do dominante e o saber do dominado, dos que pensam e dos que executam, de uma educação para a elite e uma para o povo.

Falta um Projeto Político-Pedagógico emancipador e contra-hegemônico, que reveja as práticas de comunicação da tutoria e dos demais atores. Mas essa revisão ainda será limitada, pois requer emancipar a política de educação a distância, pois esta expressa a ideologia do capital humano na sociedade capitalista globalizada que produz recursos humanos requeridos pelo capital, pois se considera a escola apenas o lugar em que se adquirem conhecimentos técnicos necessários ao exercício da profissão. (SCHNEIDER, 2013).

A educação emancipadora, no contexto virtual, deve ser vivenciada como uma prática concreta de libertação e de construção da história. E, nesse espaço virtual, todos devem ser sujeitos aprendizes, solidários num projeto comum de 
construção de uma sociedade na qual não exista mais a palavra do explorador e a do explorado.

Diante disso, necessita-se parar e repensar sobre essa política educacional e principalmente sobre a educação a distância para não formar professores apenas com um diploma e sem conhecimento, didática e arte de ensinar.

É preciso elaborar uma lógica comunicacional interativa, que estimule o estudante à participação, facilite as trocas, a colaboração, as associações e as formulações. É fundamental a alteração de procedimentos tradicionalistas e também a observação minuciosa das propostas de uma educação on-line construída e direcionada pelos conceitos de polifonia, interatividade e dialogicidade pensados, principalmente, a partir da obra do teórico Bakhtin (2004).

Parafraseando Marx e Engels (2002, p. XIII), uma educação a distância emancipatória no ciberespaço pressupõe, necessariamente, elevar o aprendente "à sua verdadeira natureza genérica", de modo a realizar suas potencialidades, gerando a necessidade de desprendê-lo das alienações que o cindem consigo mesmo e o separa dos demais aprendentes do seu gênero, uma vez que o conhecimento alienado não é educação, mas, deseducação.

E para isso, a comunicação precisa ser percebida como um diálogo comunicativo, autêntico, dialógico, não pode ser muda, silenciosa e com palavras falsas, porque dessa maneira estaremos caminhando para uma sociedade da “incomunicação". (GALEANO, 2006).

Por fim, a possibilidade de ocorrer uma comunicação emancipadora nos cursos de formação de professores somente será possível a partir de uma política de formação que articule teoria e prática, discurso e realidade em busca de uma construção coletiva do sentido da práxis que transforma e supera a hegemonia tecnicista, de gerenciamento e da massificação. E isso vai fazer com que se supere a educação a distância, criando uma metodologia que incorpore as tecnologias sem distância distante.

\section{REFERÊNCIAS}

BAKHTIN, Mikhail. Marxismo e filosofia da linguagem. São Paulo: Editora Hucitec, 2004.

BARRETO, Raquel Goulart. Tecnologias educacionais e educação a distância: avaliando políticas e práticas. Rio de Janeiro: Quartet, 2001. 
BRASIL. Instituto Nacional de Estudos e Pesquisas Educacionais Anísio Teixeira. Censo da Educação Superior: 2010 - resumo técnico. Brasília: Instituto Nacional de Estudos e Pesquisas Educacionais Anísio Teixeira, 2012. Disponível em: $<$ http://download.inep. gov.br/educacao_superior/censo_superior/resumo_tecnico/resumo_tecnico_censo_educacao_superior_2010.pdf>. Acesso em: 13 out. 2012.

BRASÍlLIA. Projeto Acadêmico do Curso de Pedagogia a Distância. Faculdade de Educação, UnB, 2011.

DIAZ BORDENAVE, Juan E. Além dos Meios e Mensagens: Introdução à comunicação como processo, tecnologia, sistema e ciência. Petrópolis: Editora Vozes, 1983.

FRANCO, Maria Laura P. B. Análise do Conteúdo. Brasília: Líber Livro Editora, 2005.

FREIRE, Paulo. Educação e Mudança. São Paulo: Paz e Terra, 2011.

FREIRE, Paulo. Pedagogia do oprimido. Rio de Janeiro: Paz e Terra, 2005.

FREIRE, Paulo. Educação como prática da liberdade. 30. ed. Rio de Janeiro: Ed. Paz e Terra, 2007.

FREIRE, Paulo. Extensão ou comunicação? Trad. Rosisca Darcy de Oliveira. São Paulo: Paz e Terra, 2006.

FREITAS, H. C. L. de. A (nova) política de formação de professores: a prioridade postergada. Educ. Soc., Campinas, v. 28, n. 100, Especial, p. 1203-1230, out. 2007.

GADOTTI, Moacir. Perspectivas atuais da educação. São Paulo Perspec. [on-line], v. 14, n. 2, p. 03-11, abr./jun. 2000. Disponível em: <http://www.scielo.br/scielo. php?script $=$ sci_arttext\&pid $=$ S0102- 8392000000200002\&lng=es\&nrm $=$ iso $>$. Acesso em: 26 jun. 2006.

GALEANO, Eduardo. A caminho de uma sociedade da incomunicação? In: MORAES, Denis (Org.). Sociedade Midiatizada. Rio de Janeiro: Mauad, 2006. p. 149-154.

KELLNER, Douglas. Cultura da mídia e triunfo do espetáculo. In: MORAES, Denis (Org.). Sociedade Mediatizada. Rio de Janeiro: Mauad, 2006.

KOSIK, Karel. Dialética do Concreto. Rio de Janeiro: Paz e Terra, 2002.

LDB. Senado Federal. Dispõe sobre a Lei de Diretrizes e Bases da Educação Nacional $n^{\circ}$ 9.394/96. Brasília, 1996.

LIMA, Venício A. Comunicação e cultura: as ideias de Paulo Freire. 2. ed. rev. Brasília: Editora Universidade de Brasília: Fundação Perseu Abramo, 2011.

MARX, Karl; ENGELS, Frederich. Ideologia alemã. 2. ed. Trad. Luiz Cláudio de Castro e Costa. São Paulo: Martins Fontes, 2002.

MORAES, Raquel de A.; SANTOS, Gilberto Lacerda. A educação na sociedade tecnológica. In: SANTOS, Gilberto Lacerda (Org.). Tecnologias na educação e formação de professores. Brasília: Editora Plano, 2003. v. 1. p. 11-30. 
SAVIANI, Dermeval. A pedagogia no Brasil: história e teoria. Campinas, SP: Autores Associados, 2008.

SAVIANI, Dermeval. Escola e democracia: teorias da educação, curvatura da vara, onze teses sobre educação e política. 41. ed. São Paulo: Cortez, 2009.

SCHNEIDER, Magalis B. D. Os processos comunicacionais na política de formação de professores a distância. 226 f. Tese (Doutorado em Educação) - Universidade de Brasília, DF, 2013.

TEIXEIRA, Nereu. A comunicação Libertadora. São Paulo: Edições Paulinas, 1983.

TRIVIÑOS, Augusto Nibaldo Silva. Introdução à pesquisa em ciências sociais: a pesquisa qualitativa em educação. São Paulo: Atlas, 1987.

Texto recebido em 09 de janeiro de 2015.

Texto aprovado em 14 de março de 2015. 
